F. C. Calvert hat dieser Frage dadurch năher zu kommen gesucht, dass er den Einfluss verschiedener Gase und Lösungen auf die Eier durch lange Reihen von Experimenten untersuchte, welche zu nachstehenden Ergebnissen führten: l)er Sauerstoff wirkt sehr verschieden, je nachdem er trocken oder feucht ist. Trockner Sauerstoff lässt damit behandelte Eier unverändert, während durch feuchten sich nach kurzer Zeit die Eier mit Schimmel bedecken, ihr Inneres jedoch nur dann zersetzt ist, wenn man vorher mit einer Nadel ein Loch in die Schale gestossen hatte.

In feuchtem Stickstoff können die ganzen, wie die angebohrten Eier sich drei Monate lang unzersetzt erhalten. Dic ganzen Eier bedecken sich mit einem Flaum von Penicillium, aber das Innere bleibt gesund. Bei durchbohrten Eiern wird der Inhalt etwas zersetzt, und man findet in ihm Vibrionen, jedoch kein fremdes Gas. In Wasserstoff bedecken sich die ganzen, wie die angebohrten Eier mit einem leichten Flaum, aber der Inhalt bleibt gesund. Unverletate Eier, wie durchbohrte haben sich in Kohlensäure vortrefflich conservirt, auf der Oberfläche erschien keine Spur von Penicillium. Das Resultat blieb dasselbe, ob die Kohlensäure feucht oder trocken, war. Leuchtgas verhielt sich wie Kohlensäure. In ciner Lösung von Chlor $(1 / 500)$ zeigten sich die Eier nach $6 \mathrm{Mo}$ naten in einem verschlossenen Gefässe vollkommen gut erhalten, in einer offenen Flasche jedoch bedeckten sie sich schon nach einer Woche mit Schimmel. Chlorkalklösung, Kalkwasser, und eine Lösung von schwefligsaurem Kalk geben nur geringen Schutz. In Carbolsäurclösung $(1 / 500)$ gebrachte Eier zeigten nach längerer Zeit keine Veränderung. (Comptes rendus t. LXXVII. p. 1024. Dingler's Polyt. J. Bd. CCXI. p. 408.).

$K r$.

\title{
Ueber Sehwammfischerei.
}

Ungeachtet der grossen und stets steigenden Menge von Schwämmen, welche alljährlich den Meerestiefen im türkischen und griechischen $\Lambda$ rchipel entnommen wird, hat man nach der Angabe englischer Sachverständigen bis jetzt noch keine Abnahme dieses hochgeschätzton Naturproductes beobachtet, dessen Sammlung die beinahe ausschliessliche Nahrungsquelle der Bevölkerung einer Reihe der betreffenden Inseln ausmacht. Die Ausbeute hat sich sogar in den letzten Jahren durch die Anwendung verbesserter Taucherapparate französi- 
scher und besonders englischer Fabrikation noch gesteigert, ohne dass jedoch hierdurch wieder umgekehrt ein extensiverer Betrieb dieser Arbeit veranlasst worden wäre. Es sind nemlich durch die gesteigerte Production die Preise der Badeschwämme während der letzten Jahre an den Versandtlokalitäten so erheblich gesunken, dass die schwammfischende Bevölkorung nicht mehr in der Lage ist, die zur Vergrösserung ihrer Bootflottille und zur Anschaffung der kostspieligen 'Taucherapparate erforderlichen Kapitalien anzusammeln, so dass also die verbesserte Tauchermethode das Correctiv gegen Ueberproduction in sich selbst trägt. Ein neuer Taucherapparat kostet gegen 3000 Thaler, eine immerhin erhebliche Summe in durchschnittlich armen und auf ausländisches Kapital angewiesenen Territorien. Im Jahr 1872 waren im griechischen und türkischen Archipel 110 Taucherapparate bei einer Gesammtzahl von 468 Booten im Diensto der Schwammfischerei. Das hierdurch reprüsentirte Betriebskapital belief sich auf die runde Summe von 800,000 Thalern. Die eigentliche Arbeitszeit der Schwammfischer ist auf den Sommer beschränkt, nur eine klcine Anzahl von Booten betreibt die Sache auch während des Winters, natürlich ohne Taucher, mit Hilfe von Zugnetzen. Die Hauptmasse und die beste Qualität der Schwämme geht nach England, wohin z. B. im Jahr 1870 volle 600,000 Pfund in einem Durchschnittswerthe von $1 \frac{2}{3}$ Thaler per Pfund versendet wurden, während der europäische Continent und Amerika geringere Posten direct bezogen. (The Chemist and Druggist. March 1874.).

Dr. G. V.

\section{Löschung der Petroleumflamme dareh Chloroform.}

Bei Gelegenheit von Untersuchungen über die Diathermanität verschiedener Flüssigkeiten machte $\mathrm{C} . \mathrm{Ommeganck}$ die bemerkenswerthe Entdeckung, dass entflammtes Petroleum durch Chloroform sofort gelöscht werden kann. Auf Grund angestellter Versuche muss die Angabe der chemischen Handbücher, es sei das Chloroform nur wenig und nur unter besonderen Bedingungen brennbar, dahin berichtigt werden, dass es nicht nur im vollkommen reinen und alkoholfreien '/ustande absolut nicht brennbar ist, sondern dass sogar ein 'Lusatz von ihm anderen leicht entzündlichen Flüssigkeiten ihre Brennbarkeit benimmt. Wird es mit dem fünffachen 